\title{
El emblema de lo privado Notas sobre filosofía política y crítica feminista
}

\author{
MARIA-XOSÉ AGRA \\ Universidad de Santiago
}

\begin{abstract}
Las mujeres se convirtieron en el simbolo de la fragilidad que tenta que ser protegida del mundo extenior (el publico): se habian transformado en el emblema de to privado.
\end{abstract}

L.YNN HUNT

El reciente y nada desdeñable desarrollo del pensamiento feminista se ha dejado sentir notablemente en el ámbito de la filosofía política, tanto en lo que respecta a las concepciones tradicionales como a las contemporáneas.' Ello, obviamente, no es fruto de la casualidad sino del potencial crítico y analítico que representa hoy en día el feminismo, cuya aportación y amplia producción difícilmente, incluso para quienes no son feministas, puede ser pasada por alto. Como punto de partida, es importante destacar que la filosofía política feminista no es monolíti$\mathrm{ca}$, adopta diversas formas en función de las diferentes tendencias de la teoría feminista, como señala C.R. Sunstein, ${ }^{2}$ la diversidad es una de las características más sobresalientes de la teoría política feminista. Ahora bien, teniendo en cuenta esto, se pueden resaltar dos grandes líneas de intervención.

De una parte, el esfuerzo de relectura y reinterpretación de los textos clásicos, examinando los textos filosóficopolíticos bajo el prisma de la experiencia práctico-política feminista e insistiendo en la necesidad de incorporar en la historia de la disciplina textos generalmente excluidos, así como las obras de las teóricas del feminismo, ante el olvido sistemático de los ires siglos en que el feminismo viene siendo parte del desarrollo de la moderna filosofía política, frente al no reconocimiento y la persistente invisibilidad. De otra parte, la revisión de los conceptos y categorias fundamentales: consentimiento, igualdad, justicia, derechos, poder, público-privado, ciudadanía, democracia, etc. y la inclusión de nuevos temas: aborto, sexualidad, maternidad... En general, la crítica feminista discurre desde la necesidad de inclusión en el discurso a la reconceptualización de la filosofía política misma, en cuyo trasfondo encontramos el debate en torno a la necesidad de lograr un espacio discursivo que rompa con la pretendida "neutralidad" del discurso patriarcal, sea conservador o radical, y que, en última instancia, requiere articular la relación entre feminismo y teoría o filosofía. ${ }^{3}$

Con estas pretensiones, las investigaciones y estudios feministas, distinguiéndose claramente de las discusiones o cuestiones sobre "temas de mujeres", suponen un proyecto reconstructivo y al mismo tiempo transformador. Dicho de otro modo; kla cuestión no es, indica C. Pateman, cómo las feministas crean una teoría ab initio, sino cómo desarrollamos las formas más apropiadas de crítica y nuestras propias y distintivas aproximaciones, en orden a desmantelar y transformar la teoria social y políticaw. ${ }^{4} \mathrm{Al}$ mostrar la significación política de la diferencia sexual, la construcción patriarcal de las categorías fundamenta- 
les del pensamiento político, lo que se pone en cuestión es la concepción misma de la política que anima la tradición del pensamiento político y que descansa sobre la exclusión de las mujeres. El feminismo como proyecto reconstructivo y transformador es un proyecto crítico-positivo en la medida en que trata de desarrollar alternativas a la exclusión, a la invisibilidad, tomando en consideración las experiencias de las mujeres y valorando la importancia política de las diferencias entre ellas. La teoría feminista parte de un amplio consenso sobre los problemas que aquejan a la teoría y la práctica política -constatación de la no neutralidad, de la presencia de la masculinidad que define los términos-, mas el consenso sobre los problemas no implica un consenso en las respuestas o altemativas. Dada la imposibilidad de profundizar aquí en todos los aspectos implicados en la filosofía política feminista, prestaremos atención a la crítica al liberalismo como uno de los puntos más destacables.

\section{I}

Siguiendo las dos líneas de intervención antes mencionadas, la crítica al liberalismo va a sustentarse básicamente en una relectura de los textos clási$\cos y$ en una reconceptualización del espacio asignado a las mujeres. En los numerosos estudios que pueden ser citados, la teoria liberal, en sus versiones clásicas o en las actuales, es cuestionada seriamente: construye una concepción del ciudadano como sujeto político sexualmente neutro, histórica y socialmente indiferenciado. Mediante la investigación en torno a las relaciones hombres-mujeres, política-familia y público-privado, se descubre la construcción patriarcal del liberalismo y de ahí la crítica de sus presupuestos funda- mentales, a saber, su concepción del «yo» y los términos sobre los que se establece el consentimiento. En general, la crítica se concentra en el individualismo abstracto que se esconde bajo el modelo de la ciudadanía universal.

Sin duda, una de las que más ha contribuido en este terreno es C. Pateman, quien emprende una crítica radical a dicha tradición. Su tesis básica es que el individualismo abstracto, el individuo del que nos hablan los filósofos políticos, es sexualmente indiferente en la medida en que está «descorporalizadon, la abstracción del cuerpo es necesaria si no se quiere revelar que su figura es masculina. Como ella misma indica, uno de los temas principales de sus escritos es el de que las mujeres y los cuerpos de las mujeres representan lo privado $y$, por tanto, todo lo que se excluye de la esfera pública: «En la construcción patriarcal de la diferencia entre masculinidad y femineidad, las mujeres carecen de las capacidades necesarias para la vida política. "El desorden de las mujeres" significa que ellas suponen una amenaza para el orden político y por eso deben estar excluidas del mundo público. Los hombres poseen las capacidades requeridas para la ciudadanía, en particular, son capaces de utilizar su razón para sublimar sus pasiones, de desarrollar un sentido de justicia y por tanto de mantener la ley civil, universalm.5

Así, en los textos clásicos del contrato social aprendemos que las mujeres carecen de la moralidad política requerida para crear y mantener el orden civil, social y político. Las mujeres no pueden trascender su naturaleza corporal y pasional, su inclusión en la vida pública será como mujeres. A través del recorrido por los contractualistas clásicos, C. Pateman pone de manifiesto una dimensión ignorada de la 
ficción del contrato social: la significación política de la diferencia sexual estructurada por la moderna separacion de las esferas pública y privada. Los teóricos clásicos del contrato (a excepción de Hobbes) construyen la diferencia sexual como diferencia política. La diferencia entre la libertad natural de los hombres y la sujeción natural de las mujeres.

La idea de que a partir de la libertad e igualdad de todos en el estado de naturaleza se construye el espacio político (público, convencional) y la familia (privado, natural, no político) muestra al mismo tiempo que su enorme potencia, su gran capacidad para determinar la relación hombres-mujeres. Se privilegia, tanto en los clásicos como en la actualidad, la esfera pública y se considera irrelevante la esfera privada. Se explica, así, que el contrato social original es un pacto fraternal. Los individuos en pie de igualdad y libertad se transforman en una fratermidad civil. Sus vínculos fratcrnales vienen establecidos por un interés común como varones en asegurar que el contrato sexual, la ley de derecho sexual, sea operativa. El pacto fraternal es doble: social y sexual. Lo femenino y lo masculino son teóricamente construidos en el estado de naturaleza para reflejar la deficiencia de las mujeres y conseguir de este modo el resultado deseado en la sociedad civil y política.

En el contractualismo contemporáneo aparecen los mismos problemas. La concepción de la justicia pública y la explicación del desarrollo del sentido de justicia de J. Rawls es un buen ejemplo de ello. El yo autónomo, racional, portador de derechos y deberes, como persona pública e imparcial, esto es, capaz de hacer abstracción de la individualidad e identidad concreta, se configura como un yo abstracto, desapasionado, desarraigado. El liberalis- mo de Rawls, de nuevo, privilegia la esfera pública dejando fuera la familia, la esfera privada. E, igualmente, aceptando la relación con el hermano, la fraternidad, como la relación propiamente humana. ${ }^{6}$

\section{II}

La crítica feminista al liberalismo implica una reflexión sobre una distinta tematización del yo y de la relación con el otro, que no elimine los elementos expresivos, afectivos y corporales. La crítica al individualismo abstracto, posesivo, descorporalizado o desapasionado, lleva consigo la necesaria reconceptualización del deseo, el consentimiento, la razón pública y la razón privada. ${ }^{7}$ En cierto modo, el feminismo vendría a estar cercano a las críticas que suscitan los nuevos comunitaristas a la teoría liberal; no obstante, el interés de éstos por la renovación del espacio público descansa sobre la aceptación de la irrelevancia de la esfera privada y de su separación de la pública. Desde la óptica feminista, la separación liberal-patriarcal de ambas esferas deviene un problema político y la crítica al individualismo abstracto le lleva a una política de participación.

Con otras palabras, la reconstrucción de la historia de la filosofía política no es un mero ejercicio académico sino un instrumento de inestimable valor a la hora de encarar una de las principales tareas de las teóricas feministas, esto es, a la hora de intentar desarrollar una teoría democrática en el marco de una teoria de la igualdad civil y política que asegure la plena ciudadanía. ${ }^{8}$ Ciertamente, la concepción de los individuos como libres e iguales y el lenguaje de los derechos ha constituido un buen potencial para el feminismo, no obstante, el intento de universalizar sin tomar en consideración 
las desigualdades o diferencias existentes supone en gran medida la exclusión y la no participación. La experiencia de las mujeres da buena cuenta de ello. La intersección entre teoría feminista y democrática va, justamente, a moverse entre dos polos: los valores universales y la experiencia sexualmente diferenciada, asi lo recoge Anne Phillips en Engendering Democracy."

Siguiendo a Anne Phillips se plantean las cuestiones de cómo y mediante que mecanismos se consigue la inclusión de las mujeres y la participación en la vida pública, en la democracia, para acabar con siglos de opresión. Cómo afrontar una situación, que se quiere y entiende como transitoria, para lograr la efectiva y plena ciudadanía. La posibilidad de dar respuesta a estas cuestiones requiere hablar de mecanismos de representación, de acción positivia, de cuotas y de democracia en el trabajo y en la familia. Requiere, frente a la teoría liberal, admitir que la desigualdad social afecta a la igualdad política, que la democracia participativa va mâs allá del sufragio universal y las elecciones periódicas - sin menosprecio de ello-, el famoso lema de «lo personal es político» en sus diversas interpretaciones responde a esta preocupación.

Aceptando que el debate actual gira en torno a tres posiciones: democracia liberal, democracia activa o participativa y republicanismo cívico, se constata que el feminismo levanta objeciones a cada una de estas posiciones. Feminismo y democracia constituyen un aspecto fundamental, tanto teórico como práctico, para un proyecto político que se define como emancipatorio. Anne Phillips va presentando en su libro los puntos más relevantes de la intersección entre feminismo y democracia, destacando los dilemas, tensiones y paradojas que surgen al tratar de pensar los límites de la democracia representativa, el acceso de las mujeres como mujeres, las dificultades de definir sus intereses y de establecer mecanismos, las ventajas y las limitaciones de la democracia participativa. La claridad y el empeño en no ocultar las dificultades y tensiones con que se encuentra la teoría feminista así como el instalarla de lleno en el debate contemporáneo son valores innegables de su análisis.

Discurriendo por los diferentes significados que cobra el lema de lo personal es político, se señala la redefinición de las esferas pública y privada. La igualdad política entre hombres y mujeres debe incluir cambios sustanciales en la esfera doméstica, en las responsabilidades y en los tiempos, en el trabajo en casa y fuera de ella. Así, "si la democracia significa algo más que la oportunidad de votar en las elecciones periódicas y el igual derecho a ser candidatos, tiene que implicar un grado más sustancial de participación y una más genuina apertura, sin consideración de la raza, el sexo o la clasen.10 Una concepción más amplia del poder, de su heterogeneidad y ubicuidad se vincula con ello. Esto no quiere decir' que todo sea político en el sentido de que las relaciones entre lo personal y lo político son básicas en tanto cualquier relación puede tener efectos politícos, pero de ahí no se sigue necesariamente que la relación en cuanto que ciudadanos sea igual a otras relaciones, tales como la de amistad o amor, que lo personal sea idéntico a lo político. En definitiva, el feminismo intenta cambiar y ampliar los temas y discusiones que caracterizan a la política tradicional, política es también lo que hacemos en nuestra vida cotidiana.

La argumentación de la autora insiste en que es necesaria una redefinición de las esferas privada y pública, desvin- 
cularlas de la división entre hombres y mujeres, pero esto no significa abandonar esta distinción ya que debe existir una esfera propiamente individual, reservada a nosotros mismos, pone como ejemplos la decisión de continuar o no un embarazo o las elecciones sexuales particulares. Se sitúa en una posición en la que es preciso establecer diferenciaciones, matizaciones, no se trata de polarizar o dicotomizar una vez más, ni de valorar exclusivamente lo público ni de poner sólo énfasis en la esfera privada. Lo importante es que la ecuación de lo personal con lo político amplia el debate democrático e incide en la democratización de la vida cotidiana. Es más, va a defender que todas las formas de democracia exploradas por las feministas tienen en común el querer contrarrestar la pasividad y el aislamiento que caracterizan a la experiencia de las mujeres y consecuentemente $-\mathrm{y}$ pese a las dificultades- incrementar la participación pública. Este esfuerzo por incrementar la participación se entiende como un proceso de profundización y extensión de la democracia más que como una contraposición entre democracia representativa y directa. Su análisis de la democracia en el movimiento de mujeres es muy interesante al respecto.

Quizá lo más sobresaliente de la crítica a la democracia liberal lo encontramos en la idea de que no hay un individuo neutral tras la universalidad, la abstracción oculta las diferencias de clase y más aún las de sexo. Por esta razón Anne Phillips, al igual que Iris Marion Young, ${ }^{11}$ van a sostener que la democracia no puede estar por encima de las diferencias, lo cual conlleva entender que la democracia no debe tratar con individuos sino con grupos, se parte de que la sociedad está compuesta por diferentes grupos y que estos grupos pueden desarrollar intereses diferentes: "cualquier medida que se adopte para asegurar un incremento de la representación de las mujeres es afirmar que la diferencia sexual es políticamente relevante y que la democracia debe reconocer grupos».12 Así, frente a la defensa liberal de la igualdad de oportunidades y del individuo abstracto y neutral se aboga por un modelo de democracia en el que los mecanismos de acción positiva frente a la discriminación y el sistema de cuotas o representación de grupos devienen fundamentales. En última instancia, se afirma, la filosofía política feminista ha suscitado una poderosa crítica al individualisno abstracto y al falso universalismo, abriendo nuevas vías para una política que asuma la diversidad y la diferencia. Alguna de las vías abiertas, coincidimos con Phillips, conducen de nuevo al esencialismo, sin embargo, tenemos que lograr un lenguaje político que pueda reconocer la heterogeneidad y la diferencia. El debate es crucial para el futuro del pensamiento democrático y el feminismo proporciona buenos argumentos.

\section{NOTAS}

1. De la numerosa produccion bibliografica destacaremos solo algunos: E. Kennedy \& S. Mendus: Women in Westem Political Philosophy (1987); S.M. Okin: Women in Western Political Thought (1979); J.B. Elshtain: Meditations on Modem Political Thought (1986); R. Hamilton \& $\mathbf{M}$. Barrett: The Politics of Diversity (1986); Ethics, 99, 2 (1989); C. Pateman: The Sexual Contract
(1988); The Disorder of Women (1989); C. Pateman \& E. Gross (eds.): Feminism Challenges: Sociol and Political Theory (1986); M.L. Shanley c. Pateman (eds.): Feminist Interpretations and Political Theory, (1991),

2. C.R. Sunstein: aIntroduction: Notes on Feminist Political Thoughtm, Ethics, 99, 2 (1989), p. 219. 
3. Véase, M. Gatens: Feminism and Philosophy. Polity, 1991, R. Braidotti: Paterns of Dissonance, Polity, 1991. También Pratis Intemational, 11, 2 (1991). También C. Pateman \& E. Gross (1988).

4. C. Pateman: The Disonder of Women. Dentocracy. Feninism and Political Theory, Polity, 1989, p. 4. Véase tambien, The Sexual Contract. Polity, 1988.

\section{Ibid.}

6. Véase, S. Benhabib; "El otro generalizado y el otro concretón en $\mathrm{S}$. Benhabib \& D. Comell (eds.): Teoria feminista y Teorla critica, Valencia, Edicions Alfons el Magnanim, 1990. Sobre la concepción de la justicia de J. Rawls son muy interesantes los trabajos de Susan Moller Okin: *Justice and Gender, Phitosophy \& Public Af- fairs, 16, 1 (1988), pp. 42-72 y sReason and Fee. ling in Thinking about Justicen, Ethics, 99, 2 (1989), pp. 229-249.

7. L. Coltheart: *Desire, Consent and Liberal Theorys en C. Pateman \& E. Gross, op. cit. p. 112 122. Sobre feminismo y comunitarismo, Marilyn Friedman, *Feminism and Modern Friendships: Dislocating the Community, Ethics, 99, 2 (1989), pp. $275-290$.

8. M.1. Shanley \& C. Pateman, op. cit., p. 9.

9. Polity, 1991.

10. Ibid, p. 100 .

11. 1.M. Young: "Policy and Groups Differen. ce: A Critique of the Ideal of Universal Citizenships», Ethics, 99, 2 (1989), pp. 250-274.

12. A. Phillips, op. cit., p. 150. 